\title{
A Numerical and Experimental Investigation of Flexible Micro Air Vehicle Wing Deformation
}

\author{
Bret Stanford*, Dragos Viieru ${ }^{\dagger}$, and Roberto Albertani. ${ }^{\ddagger}$ \\ Department of Mechanical and Aerospace Engineering, University of Florida, Gainesville, FL 32611-6250 \\ Wei Shyy ${ }^{\S}$ \\ Department of Aerospace Engineering, University of Michigan, Ann Arbor, Michigan, 48109-2140 \\ and \\ Peter Ifju** \\ Department of Mechanical and Aerospace Engineering, University of Florida, Gainesville, FL 32611-6250
}

\begin{abstract}
A class of micro air vehicles (MAVs), developed at the University of Florida, implements a flexible-wing approach as a viable method for dealing with environmental disturbances such as wind gusts. This paper investigates the steady-state deflection field across a membrane wing. Experimental results are found using a low-speed wind tunnel in conjunction with a visual image correlation system. Numerical models are also formulated, consisting of the first iteration of a fluid-structure interaction problem. The pressure redistribution corresponding to the wing's change in shape can be ignored for small deformations. The computational results from this single iteration are compared to the experimental deformation field, with good correlation between the two through a range of flight conditions.
\end{abstract}

\section{Nomenclature}

$\begin{array}{ll}A O A & =\text { angle of attack } \\ c & =\text { chord } \\ C_{L} & =\text { lift coefficient } \\ C_{D} & =\text { drag coefficient } \\ C A D & =\text { computer-aided design } \\ C F D & =\text { computational fluid dynamics } \\ \varepsilon & =\text { strain } \\ \varepsilon_{0} & =\text { membrane pre-strain } \\ F E A & =\text { finite element analysis } \\ M A V & =\text { micro air vehicle } \\ p & =\text { pressure }[\mathrm{Pa}] \\ S & =\text { tension per unit length }[\mathrm{N} / \mathrm{m}] \\ \sigma & =\text { stress [MPa] } \\ t & =\text { membrane thickness } \\ V I C & =\text { visual image correlation } \\ W & =\text { displacement in the } \mathrm{z} \text { direction }[\mathrm{mm}] \\ X, Y, Z & =\text { body axis Cartesian directions } \\ x, y, z & =\text { local axis cartesian directions }\end{array}$

\footnotetext{
"Research Assistant, MAE, University of Florida, Gainesville. FL 32611

${ }^{\dagger}$ Research Assistant, MAE, University of Florida, Gainesville. FL 32611

${ }^{*}$ Research Assistant, MAE, University of Florida, Gainesville. FL 32611

${ }^{\S}$ Clarence L. "Kelly" Johnson Collegiate Professor and Chair, AE, University of Michigan, Ann Arbor, MI, 48109

** Professor, MAE, University of Florida, Gainesville. FL 32611
} 


\section{Introduction}

$\mathrm{T}$ he rapid convergence of micro air vehicles to continually smaller sizes represents successful efforts along a multi-disciplinary front. Technological advances in materials, fabrication, electronics, propulsion, actuators, sensors, modeling and control have all contributed in making MAVs a viable candidate for a plethora of tasks. Ideally, a MAV should be both inexpensive and expendable, used in situations where a larger vehicle would be impractical. Military and defense employment opportunities are perhaps the easiest to envision (in the form of battlefield surveillance, bomb damage investigation, etc), while MAVs could also play a significant role in agriculture and wildlife surveillance applications. The realization of practical MAV applications is possible due to the ever-decreasing size and weight of payload components such as video cameras, chemical sensors, and autopilots.

Flexibility is a cornerstone of the micro air vehicles developed at the University of Florida ${ }^{1}$. The flight performance of flexible MAVs has indicated several desirable properties that can be directly attributed to the elastic qualities of the wing - namely, adaptive washout. Wing deformation automatically provides a measure of gust rejection (which can be observed in flight), and assists to delay the onset of stall.

The University of Florida MAV is constructed around a light-weight carbon fiber composite wing skeleton ${ }^{2}$. The skeleton is typically covered with a very thin, flexible membrane. Several different materials are suitable for this purpose, including plastic, rip-stop nylon, cloth, or latex rubber, with each providing a different level of wing flexibility. The resulting composite wing uses the carbon fiber skeleton to support the wind loading, while the membrane skin provides lift. Typical University of Florida MAVs can be seen in Fig. 1 and Fig. 2.

The method used to fix the membrane skin to the skeleton has a large contribution to the wing's deformation field, aerodynamic characterization, and controllability ${ }^{3}$. Batten-reinforced micro air vehicles (Fig. 1) constrain the membrane through the use of thin strips of carbon fiber (battens) running longitudinally through the skin. The trailing edge is left unconstrained, and thus the primary mode of deformation is bending, while the battens keep the membrane in a one-dimensional state of strain. Perimeter-reinforced MAVs (Fig. 2) constrain the membrane along the outside edge, while the interior freely deforms. This wing derives the majority of it's flexibility from billowing (change in camber), and the membrane is kept in a two-dimensional state of strain.

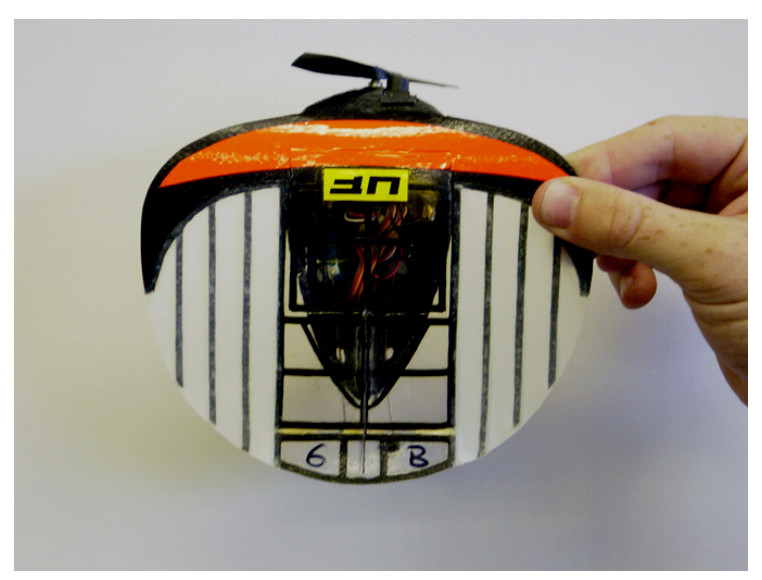

Figure 1. Batten-reinforced MAV with a 6" wingspan. Membrane skin is constrained by thin battens, and left free at the trailing edge.

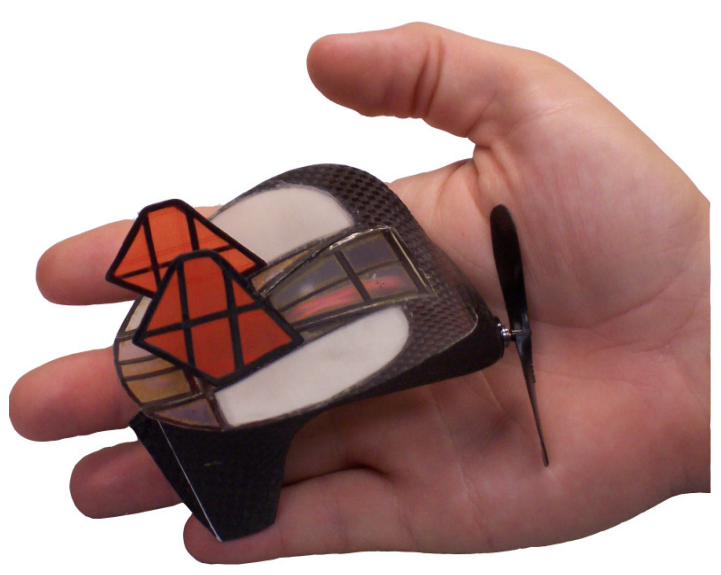

Figure 2. Perimeter-reinforced MAV with a 4" wingspan. Membrane skin is constrained along the perimeter, akin to a drumhead

A detailed understanding of the wing's deformation under various flight conditions represents a crucial step in completely exploiting the aerodynamic advantages that flexible MAVs have to offer. Attempts at numerical modeling have been successfully undertaken ${ }^{4}$, albeit with minimal experimental validation. Experimental quantification of wing deformation using projected moire interferometry ${ }^{5}$ provided good data concerning out-ofplane displacements, but was unable to recover the in-plane deformation, and thus lost the membrane strain information. Cross-correlation using stereo-triangulation ${ }^{6,7}$ was used to effectively determine the entire displacement and strain field along a membrane wing micro air vehicle ${ }^{3,8}$.

This paper proposes to reconcile the current divide evident in the literature between experimental analysis and computational modeling of flexible micro air vehicle wing deformation. Experimental results are gathered using 
stereo-triangulation in conjunction with a low speed, closed loop wind tunnel. Computational modeling is performed in the same vein as [4], although with considerable simplifications. The modeling presented here neglects time-dependent effects, non-linear membrane phenomena, and fluid-structure interaction. We are clearly aware of the types of MAV wings and flow conditions that will exploit these assumptions and negate the computational results. Therefore the experimental work presented here is tailored to the model's shortcomings in order to provide for the best possible data agreement.

\section{Motivation and Scope}

The motivation for this work is to provide a greater understanding of the role that flexibility plays in the aerodynamics of a flexible micro air vehicle. Two different approaches are taken here, and then the data from each is compared for greater insight into the working mechanisms, shortcomings, and possible improvements of both.

The first, an experimental approach, is accomplished through the use of a low-speed wind tunnel and stereotriangulation used in tandem. A flexible MAV model is placed in the tunnel, and subject to various flow conditions. A sting balance is then used to gather standard aerodynamic force and moment data. Running concurrently with these operations, the stereo-triangulation system (visual image correlation, VIC) captures images of the wing, which can be post-processed to yield full-field displacement and strain values over the elastic surface under wind loads.

The second approach aims for exactly the same data (aerodynamic loading and deformation), but is attained through numerical MAV modeling. Computational fluid dynamics (CFD) can give good estimates for the pressure loading over a micro air vehicle wing. These pressures can be integrated to yield the lift and drag. They can also be interpolated onto the mesh of a structural model (finite element analysis, or FEA) for calculation of wing deformation. This is essentially the first iteration of a fluid-structure interaction problem. Ignoring the remaining iterations will not introduce a significant amount of error, as long as the change in shape of the flexible MAV is not prominent. Comparison of experimental and numerical results can provide a wealth of information concerning model validation and enhancement.

A complete description of all of the mechanisms used to provide information pertaining to wing deformation (wind tunnel, sting balance, visual image correlation, finite element analysis, and computational fluid dynamics) will be given, as well as a discussion of the particular MAV prototype used for testing. Model validation via FEA dead weight testing and CFD aerodynamic coefficient prediction will be described. Finally, results in terms of actual membrane wing displacements (numerical and experimental) are shown for a variety of different flight conditions, as well as a discussion on the possible sources of error.

\section{Experimental Techniques and Specimen Preparation}

The information contained within summarizes the equipment and apparatus needed for accurate, full-field deformation data over a flexible wing, as well as aerodynamic coefficient data. Also discussed are the salient points concerning the selection and preparation of a specimen (micro air vehicle model) suitable for comparison with numerical simulations.

\section{A. Wind Tunnel and Sting Balance}

All tests were conducted in the University of Florida's closed circuit, low-speed, low turbulence wind tunnel. The tunnel has an $84 \times 84 \times 244 \mathrm{~cm}$ test section with optical access from the sidewalls and ceiling. The flow through the test section can be adjusted from 2 to $16 \mathrm{~m} / \mathrm{s}$, while typical testing Reynolds numbers (dependent upon wing chord geometry) range from 50,000 to 150,000. Static force and moment measurements are acquired via a $13 \mathrm{~mm}$ diameter 6-component sting balance (shown attached to a MAV model in Fig. 3). Tunnel speed, model inclination, and force/moment measurements are set, or acquired, using a dedicated PC and a multi-channel data acquisition/signal conditioning system, and in-house software developed with LabVIEW. Typical results are the accustomed aerodynamic coefficients $\left(\mathrm{C}_{\mathrm{L}}, \mathrm{C}_{\mathrm{D}}\right.$, etc). Further discussion of the relevant instrumentation can be seen in [9].

\section{B. Visual Image Correlation (VIC)}

Any experimental method used to characterize the change in shape of a flexible wing must have the capability to determine both the original wing shape and the corresponding displacement field caused by pressure loading. A visual image correlation system, developed and introduced by researchers from the University of South Carolina ${ }^{6,7}$, was used for this purpose. Visual image correlation entails deriving the displacement of a specimen under load by tracking the deformation of a randomly distributed speckle pattern previously applied to said surface. This random pattern is digitally acquired by imaging sensors before and under load. It is then mathematically processed by 
finding the region in the deformed image that maximizes the normalized cross-correlated score with respect to a small subset of the image taken while no load was applied. Recovering three-dimensional structure from two imaging sensors is called stereo-triangulation, an idea analogous to that of human vision. Prior calibration of the cameras is required (done by capturing images of a non-random speckling pattern that the vision algorithms are programmed to recognize).

The two cameras are mounted onto the top of the wind tunnel, as seen in Fig. 4, via a separate frame. Care must be taken to avoid contact between the cameras and the wind tunnel, as any vibration will negate the camera calibration. Optical access into the test section is allowed through a float (non-optic quality) glass window, whose potential detrimental effects have been well documented ${ }^{10}$. The model is illuminated by two continuous 250 Watt lamps.

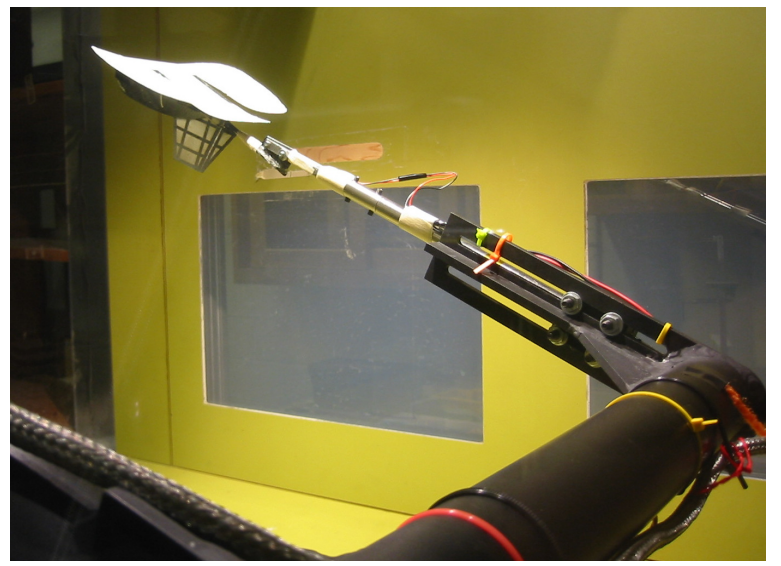

Figure 3. MAV installed in the wind tunnel.

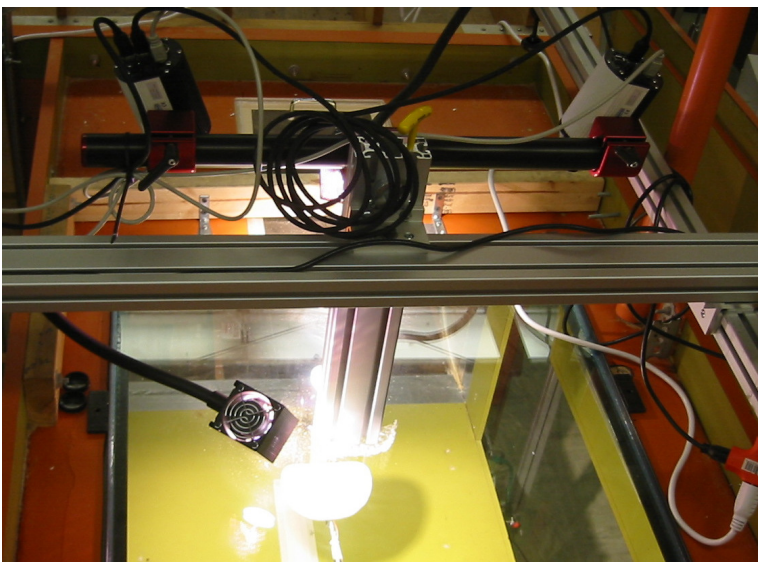

Figure 4. Cameras and lights mounted to the top of the wind tunnel.

As described above, two images are needed to obtain the full-field displacement information of a micro air vehicle wing in the wind tunnel. An un-deformed surface is generated using a reference picture, and then compared to an image of the deformed wing to yield displacement data. With this goal in mind, the reference picture should always be taken with zero wind velocity, at the specified angle of attack. If data at a new AOA is desired, it is best (though not required, as one reference image can support an infinite number of deformed images) to capture a new reference image. Failure to do so results in displacement data that reflects the inherent elasticity of the wing, in addition to the rigid body motion as the model moves from one angle of attack to the next.

Typical data results that can be obtained from the VIC system consist of the geometry of the wing surface in discrete $\mathrm{X}, \mathrm{Y}$, and $\mathrm{Z}$ coordinates (where the relevant coordinate system is a body axis, and thus the wing's angle of attack is not evident from the geometry), and the corresponding displacements along the wing. A final postprocessing option involves calculating the plane strains based upon the gradient of the displacement field. Representative VIC results of a flexible micro air vehicle wing surface before and under wind loading can be seen in Fig. 5.

Visual image correlation is a technique ideally suited for measuring the deformation over a flexible wing. This is due to its non-intrusive nature, relative ease of use, and good resolution in both displacement and strain ( $\sim 0.01 \mathrm{~mm}$ for the former and $\sim 500 \mu \varepsilon$ for the latter, although these numbers completely depend on speckle density, the distance from the cameras to the MAV surface, etc). That said, the displacement and strain data can be noisy in areas that are either nominally rigid or don't display significant movement. This is a significant concern for the current application, as the MAV deformation must be kept small to ensure good comparison with numerical data (where fluid-structure interaction effects are not carried out past the first iteration).

\section{Specimen Selection and Preparation}

A perimeter-reinforced micro air vehicle wing with a 5" wingspan was chosen for the wind tunnel testing. The deformation field of this wing is well-defined (essentially a pressurized membrane constrained along all sides) and easy to measure with VIC (the displacement field of batten-reinforced wings present problems due to areas of unconstrained membrane along the trailing edge, which can cause excessive, non-elastic deflection or vibration, as 
the tension is these areas is typically negligible). The structural modeling of these wings (discussed below) is a relatively straight forward process, thereby introducing less simulation error.

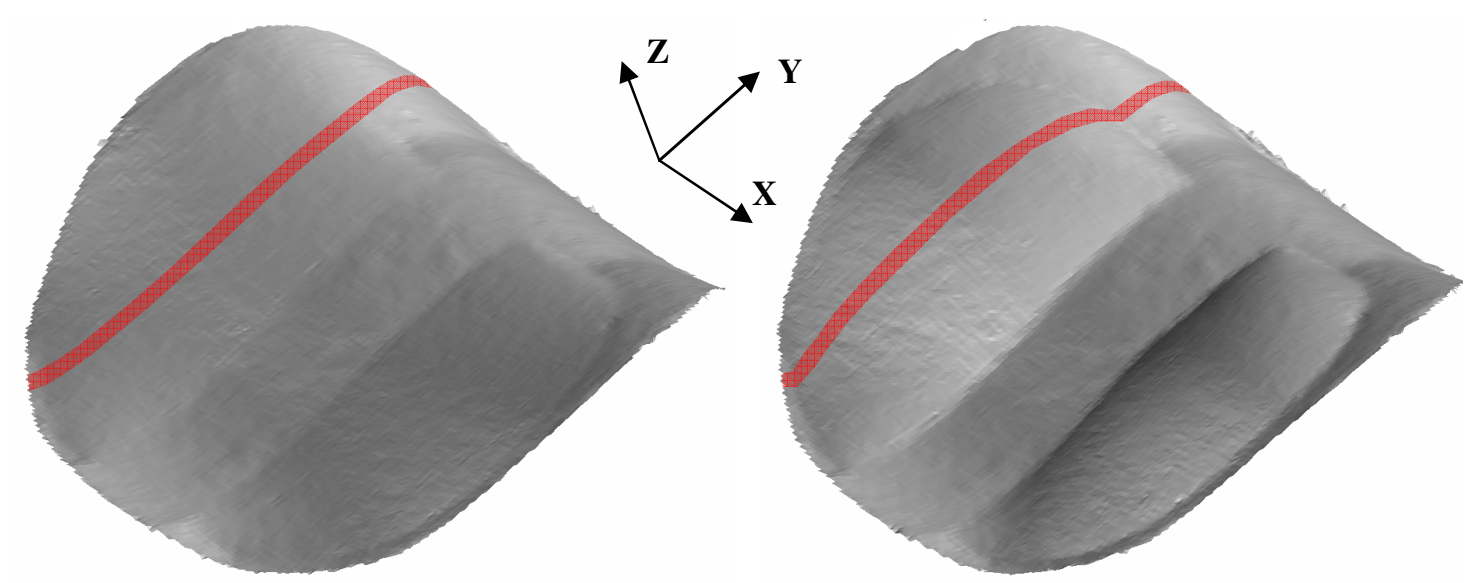

Figure 5. Perimeter-reinforced MAV surface before (left) and after (right) wind loading. Red stripe added to emphasize membrane billowing. Coordinate system is a body axis attached to the MAV.

The billowed shape of a batten-reinforced wing (Fig. 5) can be made as large or as small as needed, depending on the amount of pre-strain introduced to the membrane. As discussed above, minimal wing displacement is mandatory in order for the results obtained through VIC to be directly contrasted with CFD results (which are calculated on a completely rigid wing, albeit with the same size and shape as the wind tunnel specimen).

The construction specifications of the MAV can be seen in Fig, 6. The leading edge, perimeter, and center of the MAV wing are built from 6 layers of bi-directional composite carbon fiber plies, each in the $\left[ \pm 45^{\circ}\right]$ orientation. Fixed to this skeleton through spray adhesive is a very thin $(\sim 0.1 \mathrm{~mm})$, isotropic, pre-strained sheet of latex rubber. The differences between this model and a MAV built for flight testing purposes are minor. The center of a flight worthy micro air vehicle wing is typically fastened to the fuselage. Thus, it would not be constructed of rigid carbon fiber, but a hatch would be built in for easy access to the payload (this can be clearly seen in Fig. 2). In addition, a flight-worthy MAV would never be constructed from 6 layers of carbon fiber (two layers is typical, plus a strip of $\operatorname{Kevlar}^{\circledR}$ on the leading edge to prevent fracture upon impact), out of consideration for vehicle weight. The reasoning here for such a thick wing is a reflection of potential structural modeling error: it is desired that the majority of elastic wing deflection due to wind loads come from membrane billowing. Modeling the bending and twisting of carbon fiber composite laminates does not present a strenuous challenge, but the emphasis in the current is work is placed squarely upon the viability of uncomplicated CFD and FEA simulations for direct comparison with experimental data.
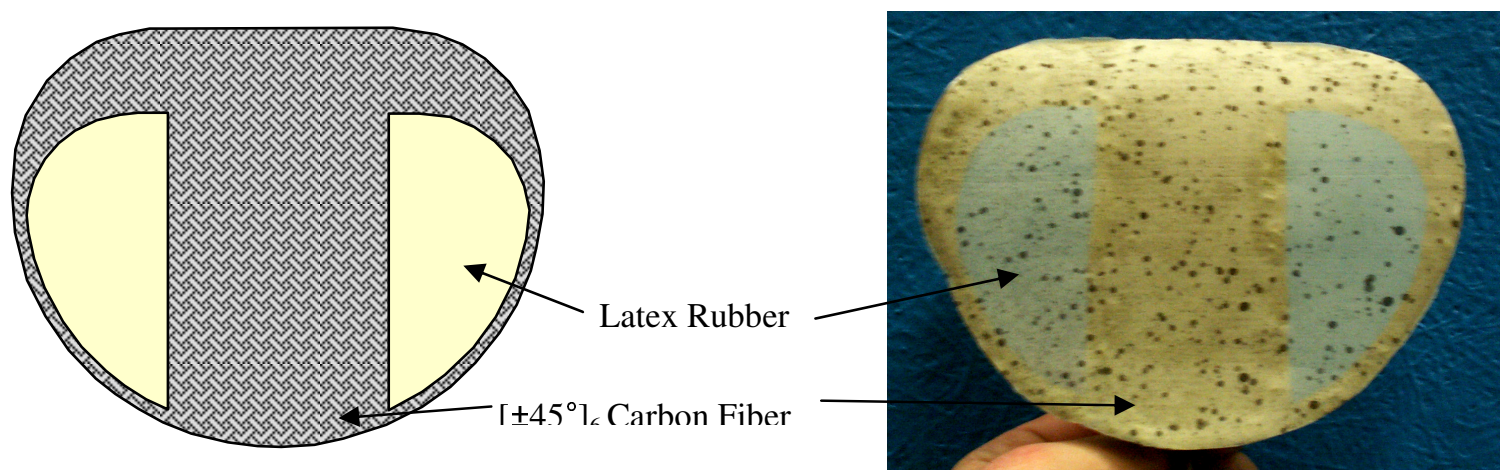

Figure 6. Construction specifications of a perimeter-reinforced MAV (right), and a specimen prepared for VIC analysis (left). 
A detailed scheme for preparation of the specimen for visual image correlation experiments is given in [3]. Prior to adhering to the carbon fiber skeleton, the membrane rubber is speckled with a flat black paint. As one speckle is typically not connected to another, the random pattern is not thought to significantly affect the elastic qualities of the membrane. If information concerning the pre-strain in the latex wing is desired, a reference picture (for future VIC work) should be taken before the membrane is glued to the carbon-fiber skeleton. A picture of a fully speckled MAV wing is given in Fig, 6.

\section{Numerical MAV Modeling}

The content described below gives an overview of the models used to simulate the behavior of a flexile wing in steady level flight (namely computational fluid dynamics and finite element analysis), as well as discretization schemes, constitutive equations, and assumptions.

\section{A. Computational Fluid Dynamics}

The three-dimensional, incompressible, viscous Navier-Stokes equations written in curvilinear coordinates were solved for steady laminar flow over a rigid micro air vehicle with a wing span of 5 inches. In keeping with tests performed in the wind tunnel, neither the fuselage nor the propeller was taken into account. The wing geometry used for computations is a faithful CAD representation of the wing designs seen in Fig. 2 and Fig. 6 (the same CAD file was used to mill the actual wing mold, thus minimizing error along this front), but the wing areas composed of latex membrane are simply modeled as rigid. As elaborated in prior sections, the perimeter-reinforced MAV wing allows for complete control of the magnitude of membrane billowing in the wind tunnel. Keeping it as small as possible (though not so minimal that the displacements cannot be measured by VIC) implies that the differences between the actual pressure distribution over a membrane wing and that computed over a rigid airfoil will be minimized.

The computational domain can be seen in Fig. 7, with the MAV wing (red) enclosed within. Inlet and outlet boundaries are clearly marked by the flow vectors. The shown configuration is that for $0^{\circ}$ angle of attack simulations. For any other AOA, the lower and upper surfaces will also see a mass flux (this is a more straight forward approach than re-meshing for each new AOA). The side surfaces are modeled as slip walls (these walls impart no friction into the flow, and thus no boundary layer forms). The dimensions of the computational domain are given in terms of the root chord length, $\mathbf{c}$, and are all placed far enough from the MAV so as not to effect the flow. Many of these boundary conditions represent a divergence from the actual flow conditions in the UF wind tunnel, but these differences are not thought to play a significant role.

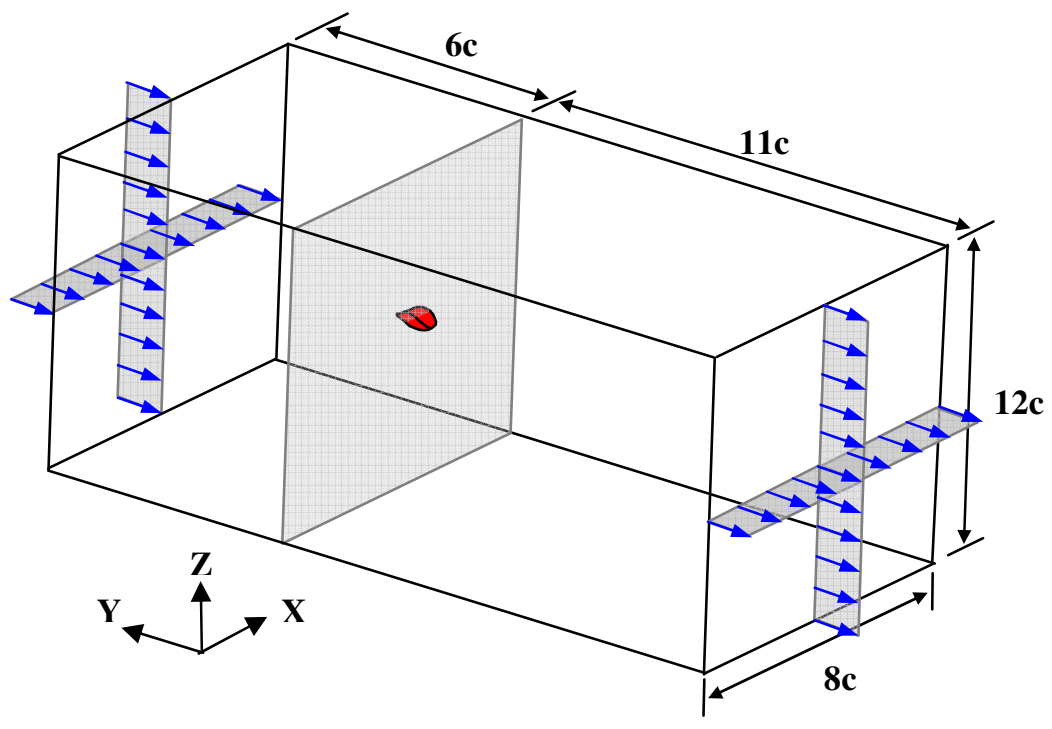

Figure 7. Computational domain and flow conditions at $0^{\circ}$ AOA. All dimensions are given in terms of the root chord length. At higher AOA, the bottom and top surfaces also see a mass flux.

In the interest of simplicity at little expense to accuracy, symmetry is exploited by modeling only half of the computational domain (the plane of symmetry is also modeled as a slip wall). A detailed view of the grid 
(approximately 210,000 nodes fill the entire domain, with $42 \times 31$ nodes on the wing surface) can be seen in Fig. 8 . As detailed in [11] and [12], a well-developed pressure based solver is employed. Further particulars concerning the computational modeling of flow over a rigid 5 inch micro air vehicle wing can be found in [13].

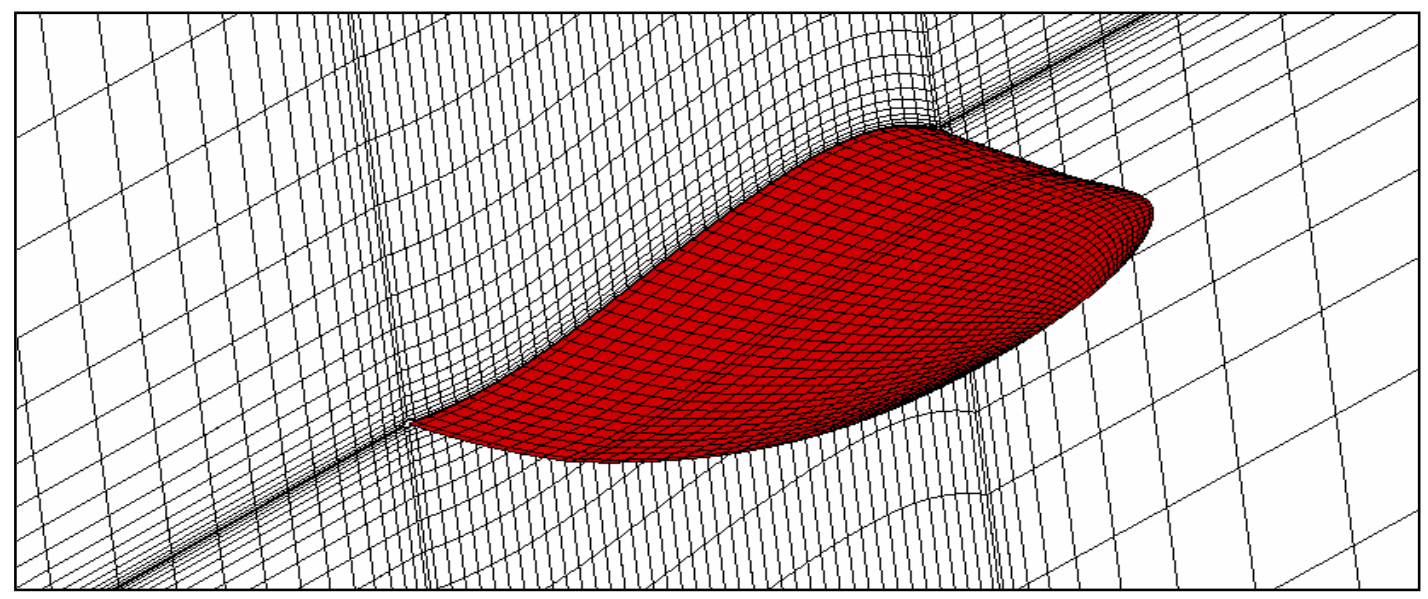

Figure 8. Detail of the mesh used for the fluid solver, near the wing surface.

\section{B. Finite Element Analysis}

The MAV wing as shown in Fig. 6 is slightly simplified for structural modeling purposes. Regions of composite carbon fiber are modeled as rigid (and are thus largely ignored by the finite element formulation, only serving to provide a boundary condition to the membrane wing). Thin membrane modeling potentially represents a significant challenge, as both geometrical and material non-linear formulations may be imperative ${ }^{14,4}$. The former arises when a membrane deforms to the point that the pressure loads significantly change direction, the latter due to the fact that thin latex rubber is a hyper-elastic material. The stress-strain curve of a hyper-elastic material is non-linear, but follows the same path in loading and unloading (below the plastic limit, which is significantly higher than in metals).

That said, the work presented here attempts to formulate an accurate membrane model in a linear fashion. This can be done only if both deformation and the resulting strain fields in the membrane are very small. As documented in [3], a perimeter-reinforced MAV tested at $13 \mathrm{~m} / \mathrm{s}$ and $22^{\circ} \mathrm{AOA}$ deforms, at most, by $5 \mathrm{~mm}$. This produces a maximum strain of 0.006. As this latter value is quite small, it is reasonable to construct a linear approximation of the stress-strain curve, centered about the membrane wing's pre-strain value (Fig. 9). It is important to note that we are not assuming that the strain in the MAV wing is small, only the deviations from the membrane pre-strain.

The linear constitutive equation used for membrane modeling is Poisson's equation ${ }^{15}$.

$$
\frac{\partial^{2} W}{\partial x^{2}}+\frac{\partial^{2} W}{\partial y^{2}}=-\frac{p(x, y)}{S}
$$

In the above, $\mathbf{W}$ is the out-of-plane membrane displacement, $\mathbf{p}$ is the applied pressure (wind loading, in this case), and $\mathbf{S}$ is the membrane tension per unit length. The length scale in question is the thickness, and thus $\mathbf{S}$ is a stress resultant, assumed equal in all directions (isotropy). This resultant can be calculated from the membrane's thickness, pre-strain, and the slope of the linear approximation shown in Fig. 9.

$$
\mathrm{S}=\left.\mathrm{t} \cdot \varepsilon_{0} \cdot \frac{\mathrm{d} \sigma}{\mathrm{d} \varepsilon}\right|_{\varepsilon_{0}}
$$

The mesh used to solve for the displacement along the membrane wing can be seen in Fig. 10. A general finite element formulation is given in Fig 11. A triangular membrane element is transformed from the global coordinates (the MAV's body axis) to a local system ${ }^{14}$ tangent to the triangle's plane (mandatory due to the MAV's curved surface), and the out-of-plane displacement field is found through the standard finite element method. 


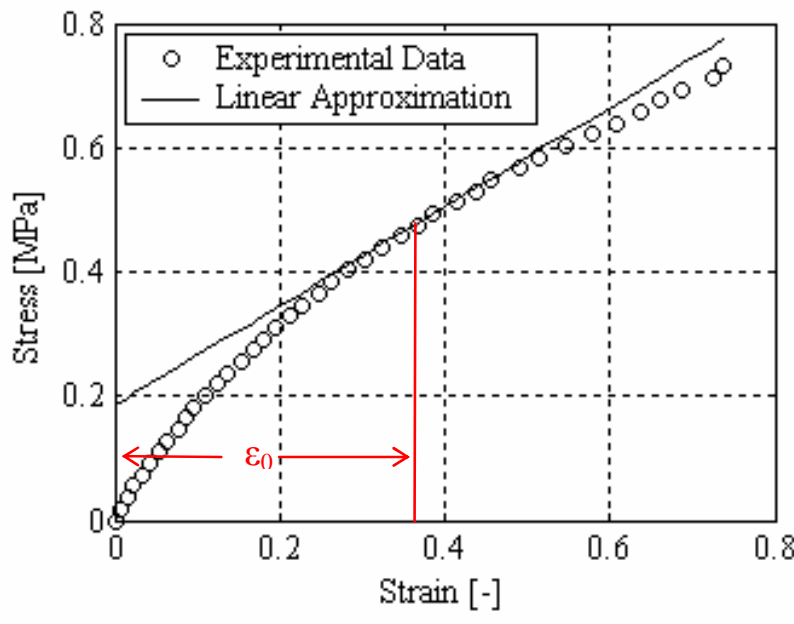

Figure 9. Stress-strain data of a hyper-elastic material in uni-axial tension. A linear approximation is constructed about the pre-strain.

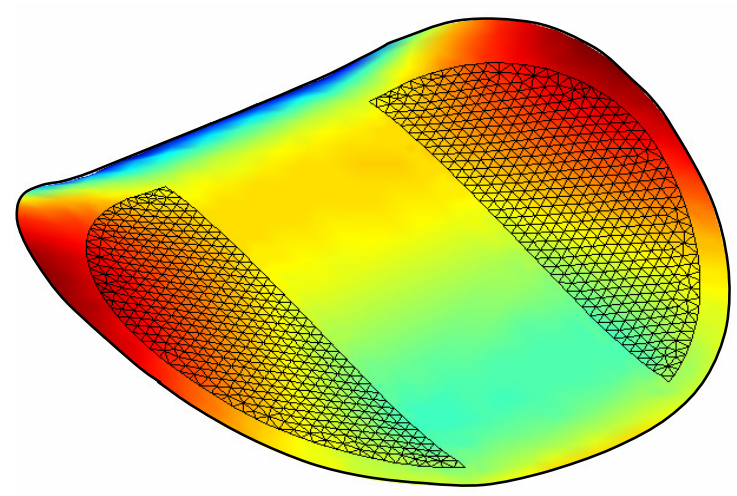

Figure 10. Finite element mesh. Color contour represents the $Z$ coordinate along the surface. Only the membrane wing is meshed.

\section{Modeling Methodology}

For a range of MAV angle of attacks and wind speeds, the CFD formulation described above is used to calculate the pressure distribution over the rigid wing surface. This pressure field is then interpolated from the structured CFD grid to the unstructured FEA grid, and then integrated, leaving the nodal forces. These forces are used to calculate the nodal displacements through the aforementioned FEA formulation. The acquired displacement field is directly comparable to experimental VIC results found at the same flow conditions.

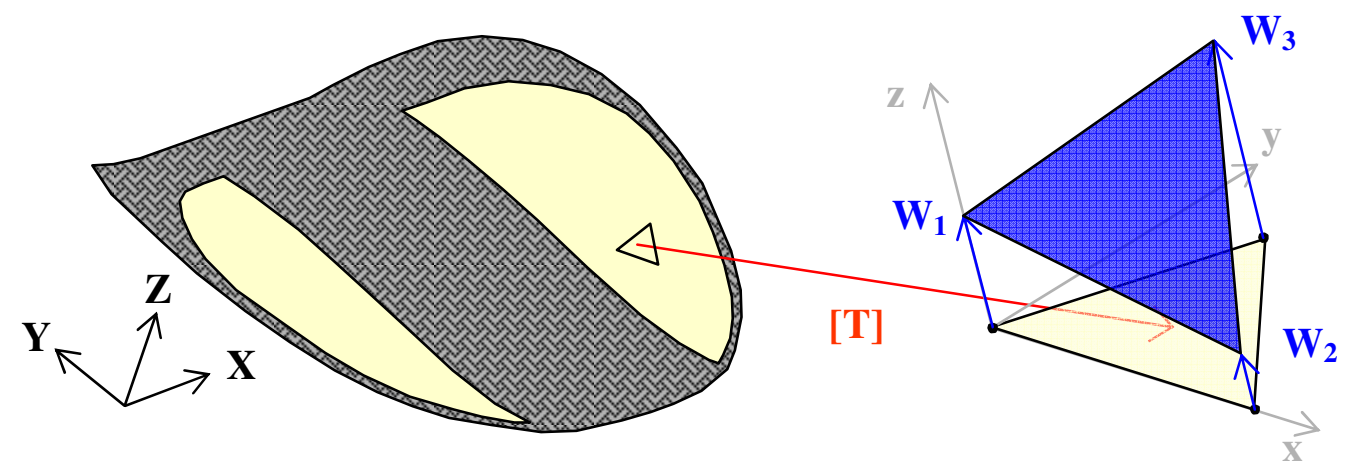

Figure 11. Finite element formulation. A triangular element on the membrane surface is transformed to a local coordinate system (via the matrix T). A finite element analysis produces the out-of-plane displacement $(W)$ at every node.

\section{Results and Discussion}

The following paragraphs detail model validation in terms of the fluid model's ability to predict lift and drag, and the structural model's capability in replicating the results of a dead weight test. Additionally, pressure distributions (numerical) and membrane deflections (numerical and experimental) are plotted for various flow conditions. This is followed by a discussion concerning the potential sources of error. Many plots are given at various wing sections, whose orientation and coordinates can be seen in Fig. 12.

\section{A. Computational Fluid Dynamics Results and Validation}

The pressure distributions over the top and bottom surface of a rigid micro air vehicle wing are given in Fig. 13 $\left(3^{\circ} \mathrm{AOA}\right.$ at $\left.13 \mathrm{~m} / \mathrm{s}\right)$, and Fig. $14\left(12^{\circ} \mathrm{AOA}\right.$ at $\left.13 \mathrm{~m} / \mathrm{s}\right)$. On the lower wing surface, at $3^{\circ} \mathrm{AOA}$, a negative pressure gradient towards the leading edge indicates a possible area of separation, and the pressure drop towards the trailing 
edge is a result of the airfoil's negative curvature, causing the flow to accelerate. On the upper surface, the negative pressure gradient at the trailing edge may signify further flow separation. At $12^{\circ} \mathrm{AOA}$, the pressure distribution over the lower surface is smoother, accelerating the flow from the leading edge towards the trailing edge to prevent separation. A strong tip vortex results in a large pressure drop towards the wingtip. Of course, the experimental setup used in this work provides no method of validating this data.

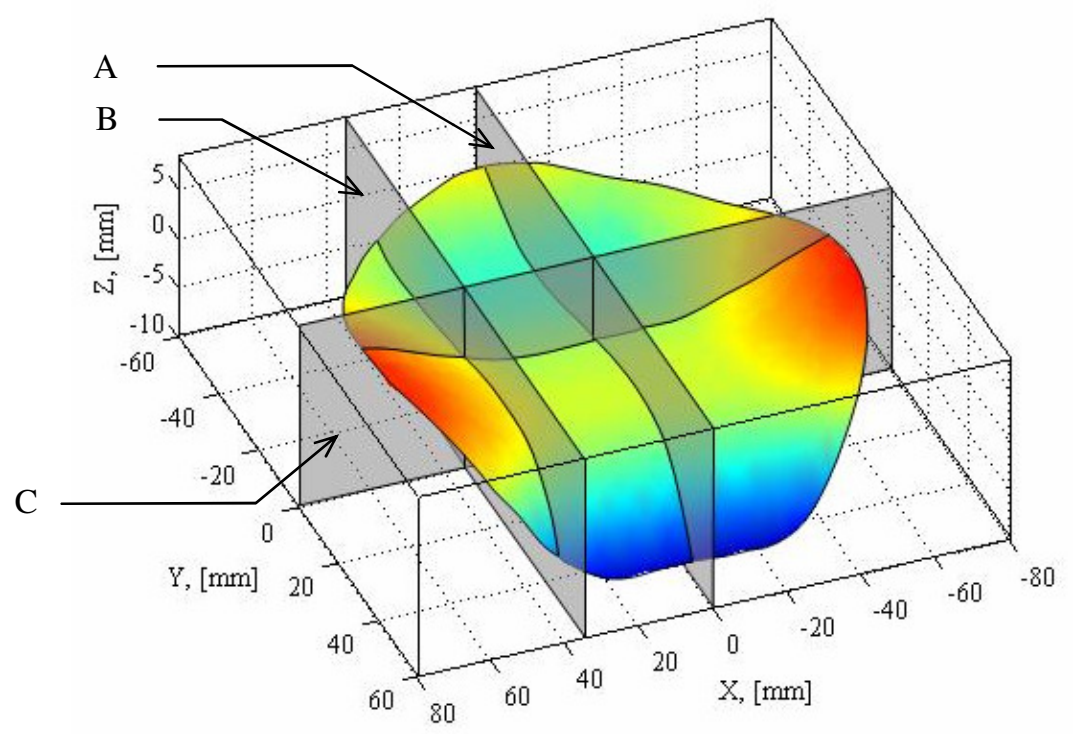

Figure 12. Plotting sections through the MAV wing. Section $A$ is through $X=0 \mathrm{~mm}$, section $B$ is through $X=35 \mathrm{~mm}$, and section $C$ is through $Y=0 \mathrm{~mm}$. The color contour represents the $Z$ coordinate along the surface.
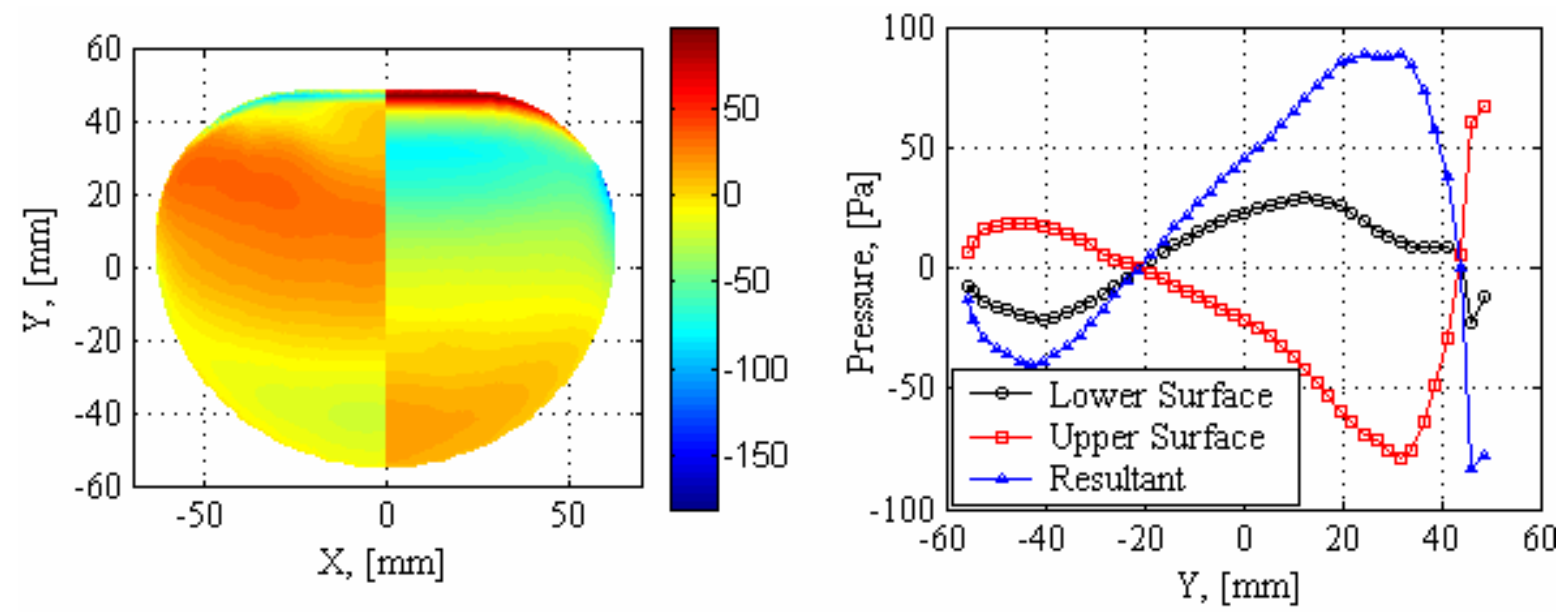

Figure 13. Pressure contours (left) and data along section A (right) for a MAV wing at $3^{\circ} \mathrm{AOA}$ and $13 \mathbf{~ m} / \mathbf{s}$. The left contour is the pressure over the lower surface; the right contour is over the upper surface.

Figures 15 and 16 present the standard aerodynamic parameters of lift and drag. Three trends are given: the first is $C_{L}$ and $C_{D}$ as a function of angle of attack found through the CFD simulations of a rigid wing. The second trend attempts to replicate these results in the wind tunnel exactly. Experimental testing was done on a nominally rigid airfoil (the same as that seen in Fig. 6, but made completely from carbon fiber). The comparison between experiment and simulation is quite good, especially for low angles of attack (where perhaps the laminar assumption is the most suitable). This similarity validates the CFD in one sense: it is well suited in predicting the flow around a rigid MAV wing. 

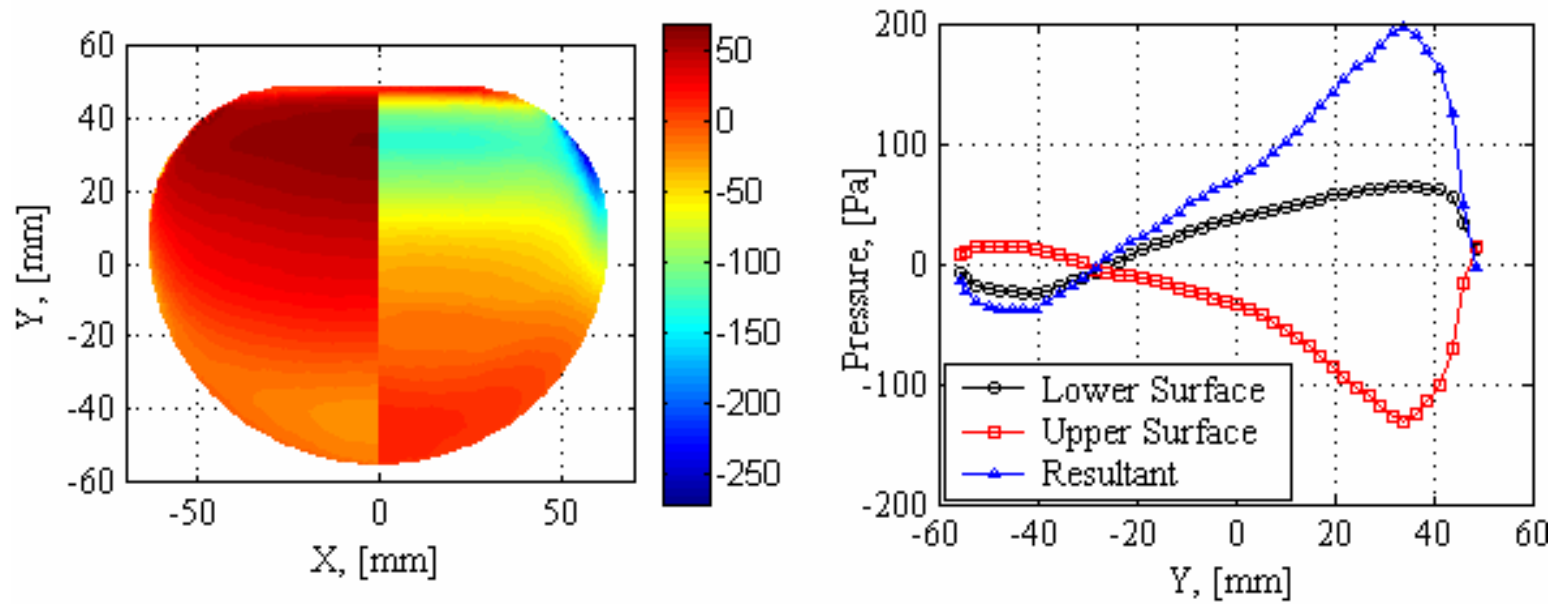

Figure 14. Pressure contours (left) and data along section A (right) for a MAV wing at $12^{\circ} \mathrm{AOA}$ and $\mathbf{1 3} \mathbf{~ m} / \mathbf{s}$. The left contour is the pressure over the lower surface; the right contour is over the upper surface.
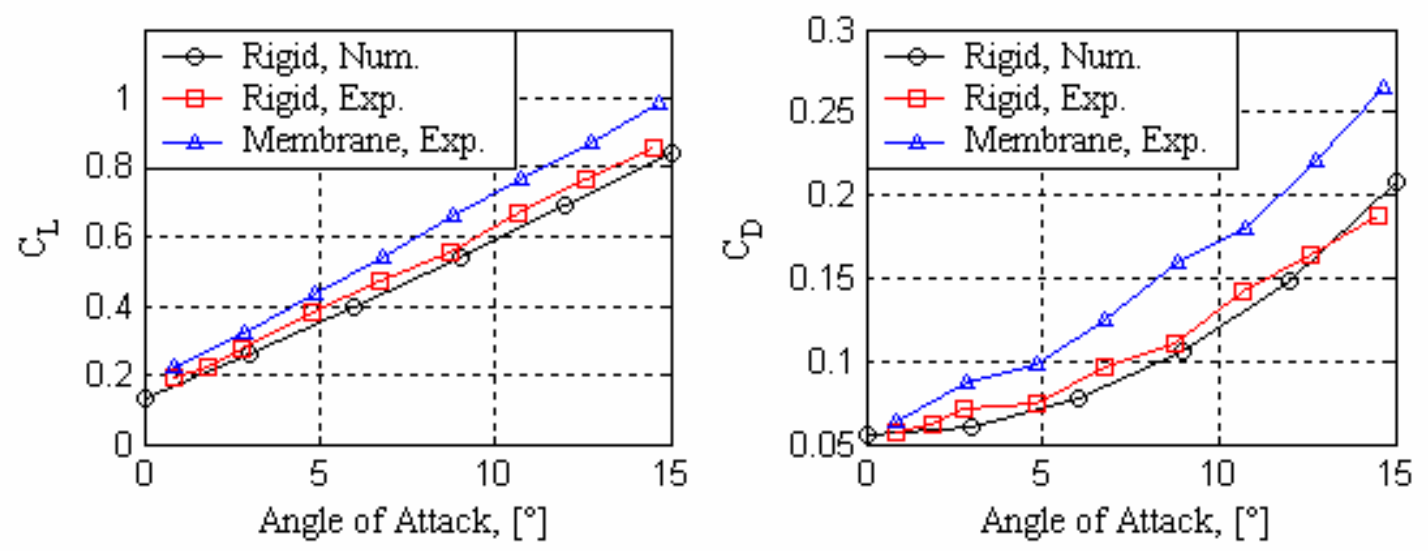

Figure 15. Coefficients of lift and drag for a MAV wing at $10 \mathrm{~m} / \mathrm{s}$. The data is found numerically and experimentally over a rigid wing, and experimentally over a flexible wing.
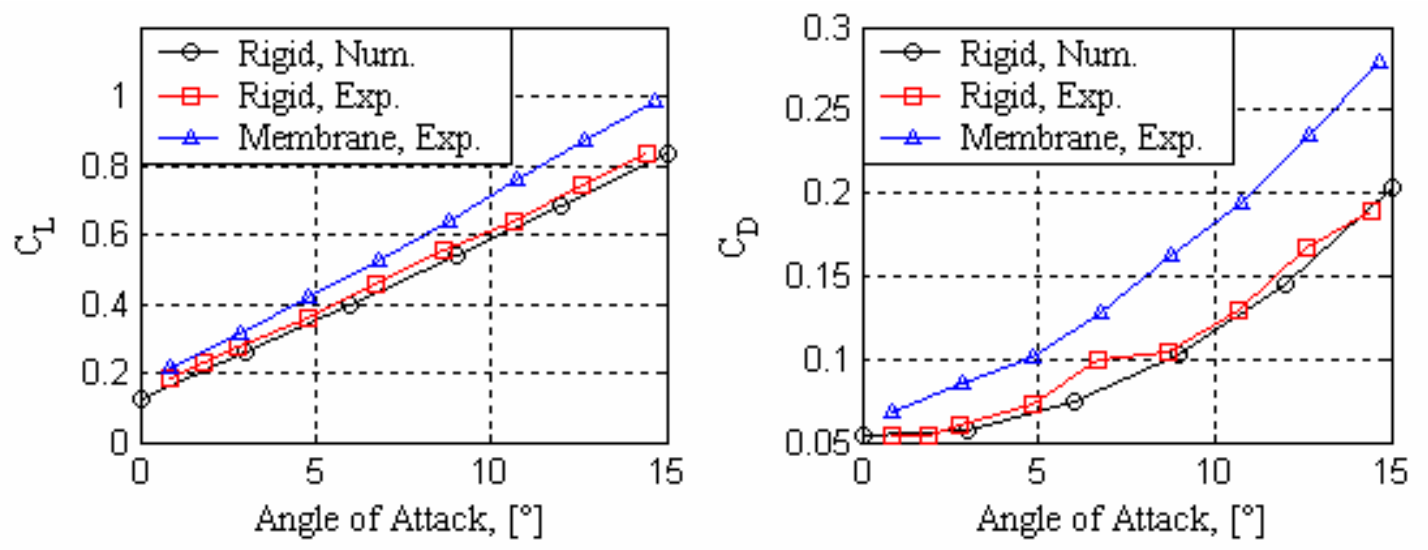

Figure 16. Coefficients of lift and drag for a MAV wing at $13 \mathbf{~ m} / \mathrm{s}$. The data is found numerically and experimentally over a rigid wing, and experimentally over a flexible wing.

The third trend line given in Fig. 15 and Fig. 16 can shed light on the appropriateness of using rigid airfoil CFD data for membrane wing applications. This trend line is the result of wind tunnel testing on the flexible MAV seen 
in Fig. 6. Predictably, both the lift (possibly due to the change in camber) and the drag (perhaps a result of the tangent surface discontinuity produced when the membrane billows, as in Fig. 5) are higher for the membrane wing, but not appreciably so. Indeed, as in the rigid airfoil, coefficients of lift and drag match up well for low angles of attack. At $15^{\circ}$ angle off attack, for $13 \mathrm{~m} / \mathrm{s}$, the CFD of a rigid airfoil under-predicts the $C_{L}$ by $15 \%$ and the $C_{D}$ by $30 \%$. Thus, using the numerical simulations of flow over a rigid MAV wing for membrane wing applications is a suitable approximation that deteriorates for increasing angle of attack.

\section{B. Finite Element Analysis Validation}

The structural model used to simulate the membrane billowing of a flexible MAV wing was validated with a dead weight test. A transverse point load was applied to the center of the left membrane wing. This is a straightforward numerical simulation. From an experimental standpoint, it was accomplished by attaching the tip of a thin string to the membrane wing, off of which a series of small weights were hung. VIC was then implemented to measure the displacement field of the wing due to the dead weight. The results from one of these tests (in terms of out-of-plane displacement, or W) can be seen in Fig. 17, with suitable correspondence between numerical and experimental data.
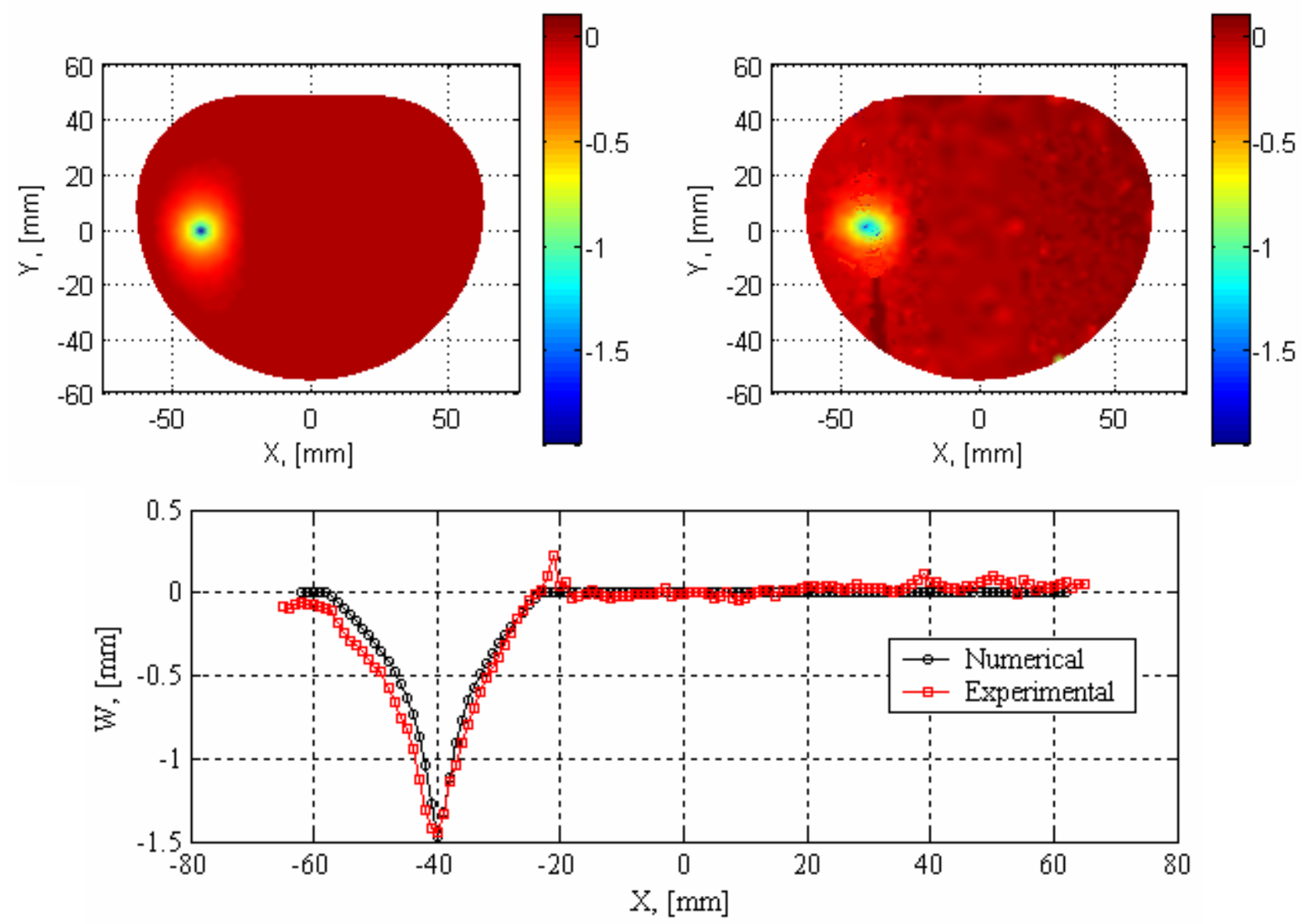

Figure 17. Deformation caused by a 3 gram weight hung from the center of the membrane wing. Numerical out-of-plane displacements (top left), experimental out-of-plane displacements (top right), displacement data along section $C$.

\section{Wing Displacement Results}

The out-of-plane displacements of a flexible membrane MAV wing are given in Fig. 18 and $19\left(3^{\circ}\right.$ AOA at 13 $\mathrm{m} / \mathrm{s})$, and Fig. 20 and $21\left(12^{\circ} \mathrm{AOA}\right.$ at $\left.13 \mathrm{~m} / \mathrm{s}\right)$. For both angles of attack, the deformation fields (numerical and experimental) match very well. Perhaps surprisingly, given the CFD performance assessment discussed above, the 
results at the higher angle off attack have a better correspondence. As previously noted, the computer simulations are only capable of modeling displacement fields within the membrane: the remainder of the wing is seen as stationary. This is an assumption that is reasonably well validated through VIC.
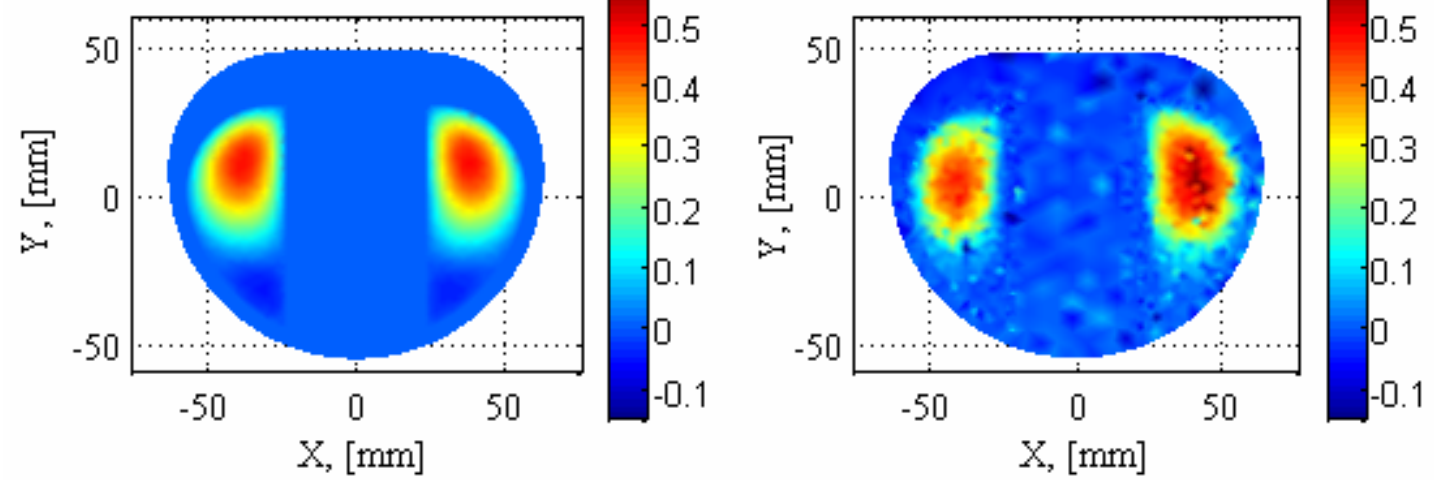

Figure 18. Out-of-plane displacement contours of a MAV at $3^{\circ} \mathrm{AOA}$ and $13 \mathrm{~m} / \mathrm{s}$. Numerical data (left), and experimental data (right).
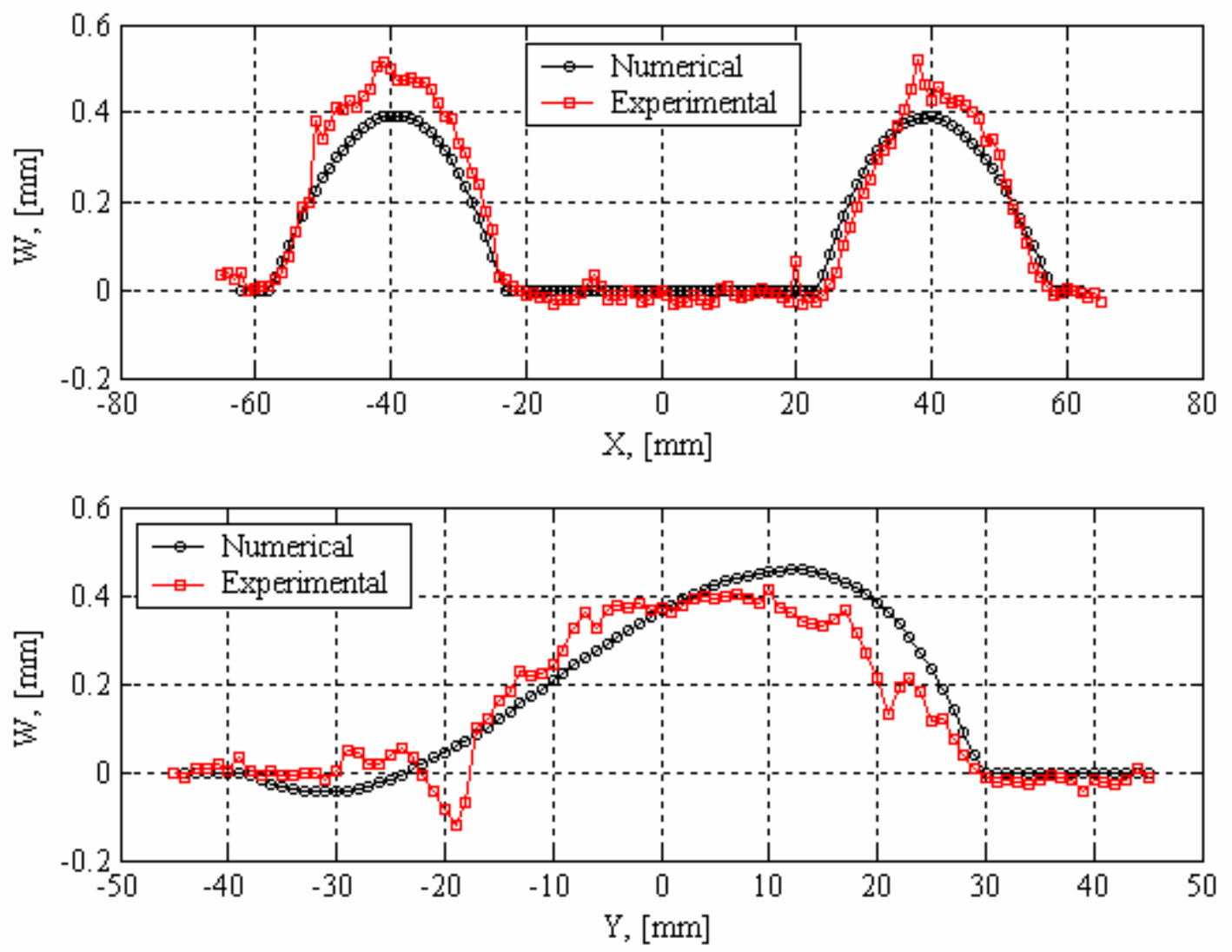

Figure 19. Out-of-plane displacement data of a MAV at $3^{\circ} \mathrm{AOA}$ and $13 \mathrm{~m} / \mathrm{s}$, at section $\mathrm{C}$ (top), and section B (bottom).

Most of the displacement measured in the regions of carbon fiber is simply noise, rather than genuine displacement. The one area of concern however, is the perimeter reinforcement. Despite its seemingly excessive construction (as discussed, a 6 layer laminate), the perimeter's width is rather small $(\sim 5 \mathrm{~mm})$, and as a result may be susceptible to small bending and twisting deformations. This is a problem that can be expected to grow with higher 
angles of attack and/or wind speeds, and is possibly evidenced in the data of Fig. 21. The perimeter's displacement on a wing at $12^{\circ}$ AOA never quite reaches zero (as it does at $3^{\circ}$, Fig. 19), instead leveling off at about $0.05 \mathrm{~mm}$. Obviously, more rigorous structural models will solve this problem, and a second major source of error has been located. As before, assuming that only the membrane section of the wing sees any deformation is a suitable approximation only at low angles of attack.
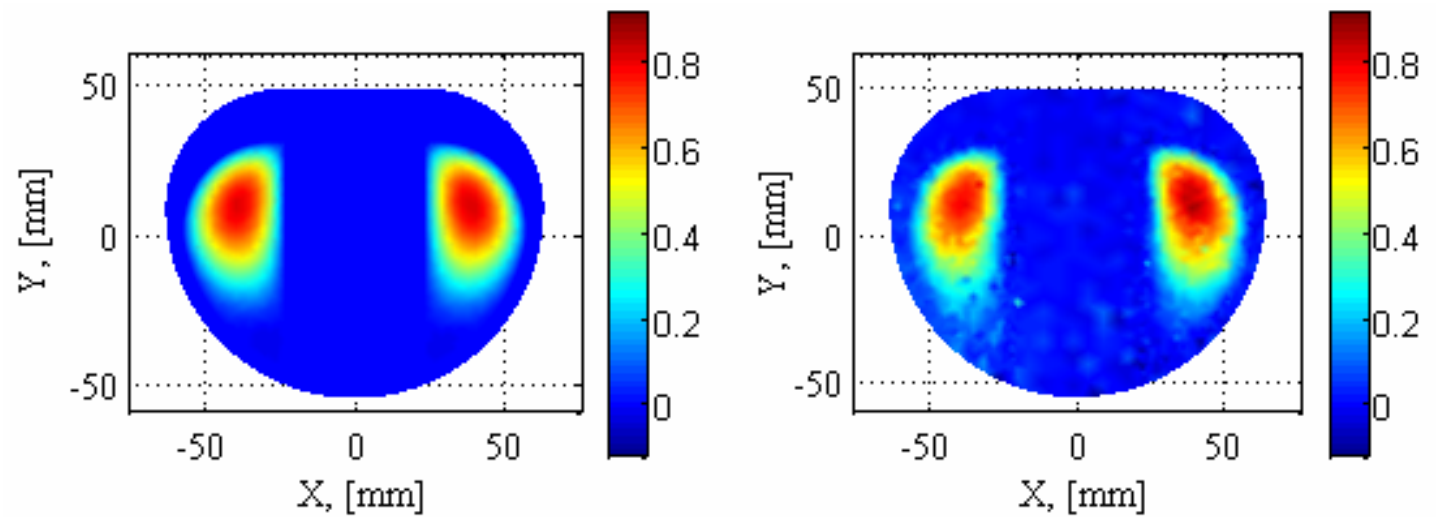

Figure 20. Out-of-plane displacement contours of a MAV at $12^{\circ} \mathrm{AOA}$ and $13 \mathrm{~m} / \mathrm{s}$. Numerical data (left), and experimental data (right).
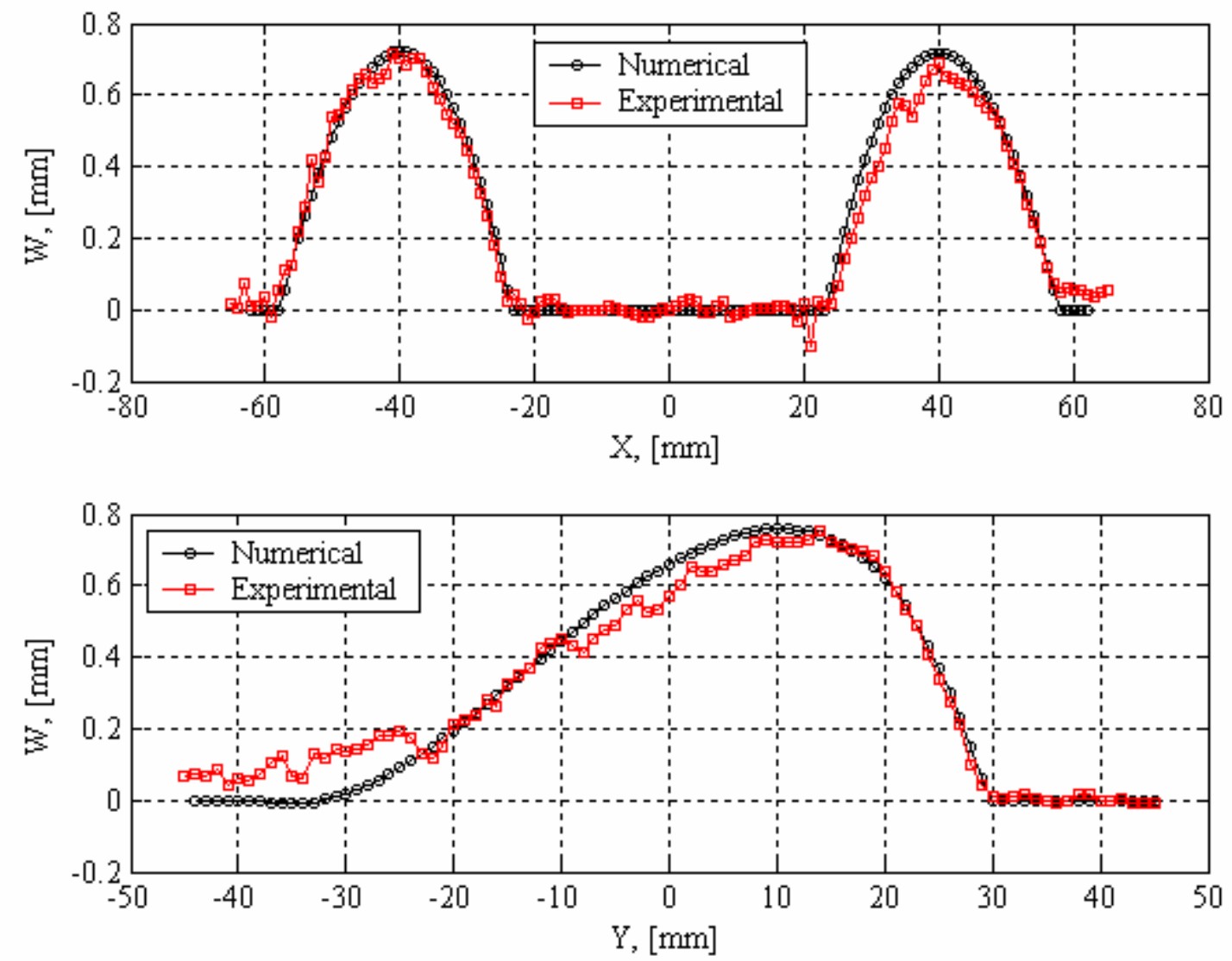

Figure 21. Out-of-plane displacement data of a MAV at $12^{\circ} \mathrm{AOA}$ and $13 \mathrm{~m} / \mathrm{s}$, at section $\mathrm{C}$ (top), and section $B$ (bottom).

Other potential errors stemming from the structural model include grid misalignment. This occurs, for example, if a particular node in the mesh is modeled as carbon fiber (rigid), but in reality lies within the membrane region of 
the wing. This error does not appear to be of concern however: the data slices given in Fig. 19 and 21 show good correspondence in the location of the points of transition from membrane to carbon fiber (indicated by a cusp in the displacement profile).

Further data, documenting the displacement field across a sweep of angle of attacks, is given in Fig. 22. In terms of the deformed shape of the billowed membrane, the numerical models predict that the trailing edge of the wing actually deforms downward for low angles of attack. This is a result of the negative pressure resultant predicted by the CFD at the trailing edge of the wing (Fig. 13). This is a phenomenon that is never witnessed through the experimental investigation (VIC), and suggests that the pressure distribution over the trailing edge as predicted by CFD is strongly dependent upon the fluid structure interaction (which is ignored here). Further deviations in membrane shape occur within the maximum camber. The position of the maximum camber as calculated through the numerical models is well-predicted at high angles of attack (Fig. 21), but placed too far forward at lower angles (Fig. 19).
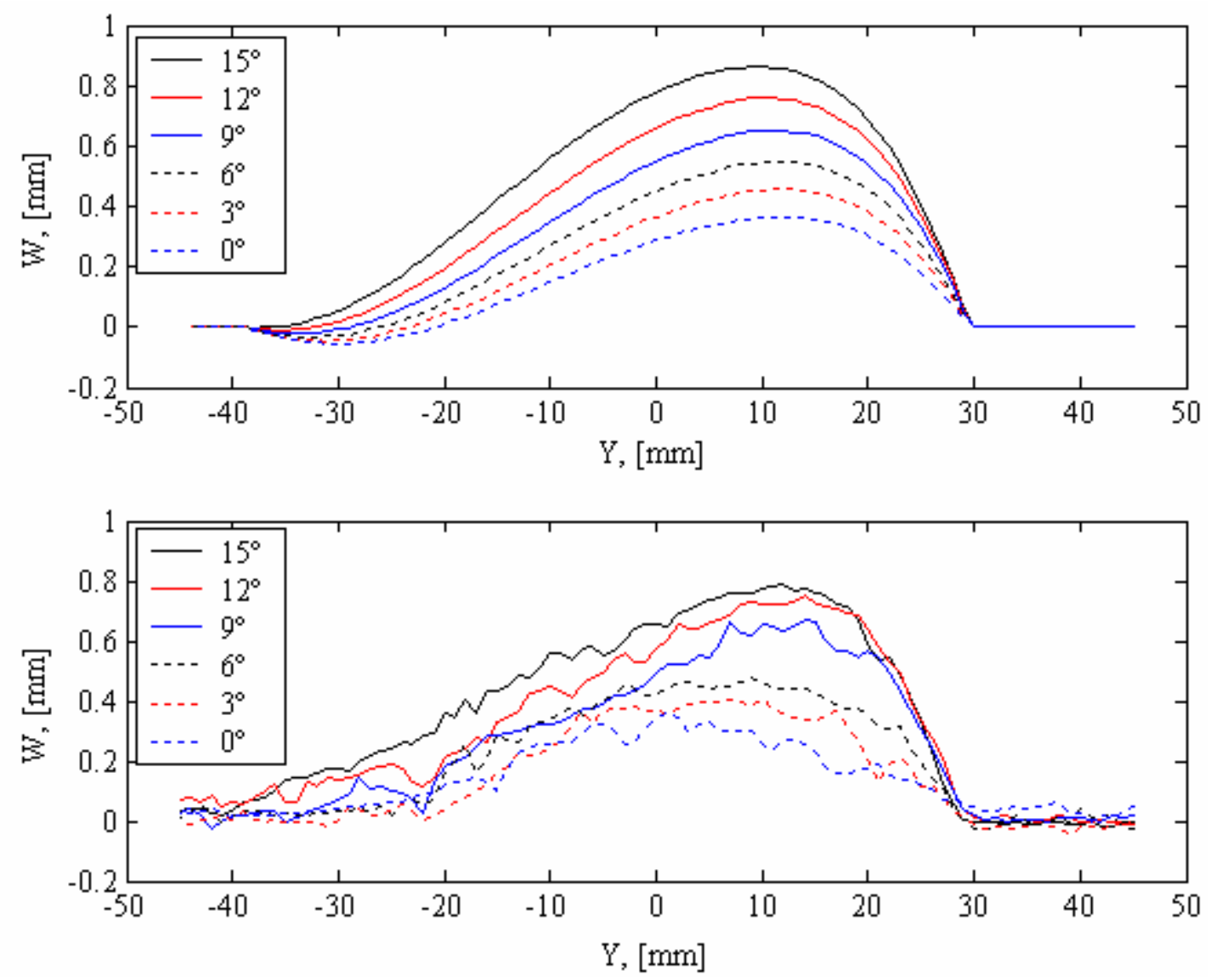

Figure 22. Out-of-plane displacement data of a MAV with a speed of $13 \mathbf{~ m} / \mathbf{s}$, at section B. Numerical data (top), and experimental data (bottom), through a sweep of angles of attack.

A final salient point concerning the data given above is the noise levels of the VIC displacement results. Membrane displacement tends to decrease with angle of attack (in the pre-stall flight regime, at least). Small displacements, as evidenced by Fig. 22, produce high noise levels. This problem could be remedied in one of two ways. The first method entails decreasing the pre-strain in the latex wing, to provide for greater (and easier to cleanly measure) membrane billowing. This is an unacceptable solution, at least in the context of the current work. If the wing changes shape in a substantial manner, then so too would the pressure distribution. This would invalidate our assumption to ignore the fluid-structure interaction. A second potential solution to the VIC noise problem is to increase the number of pixels associated with a certain area, by zooming the cameras close to the wing. This would certainly alleviate the noise levels, but then the displacement field of the entire MAV wing would have to be pieced together from several images: a tedious process, prone to errors. 
Thus an error trade off with angle of attack has been identified. From an experimental standpoint, error decreases with higher angles of attack (VIC can measure large displacements with more accuracy than small ones), but the numerical data improves as the angle of attack decreases (the smaller the displacement, the better the assumption that the pressure distribution over the wing is not largely affected by the shape change). Second order error norms are plotted in Fig. 23, and it bears out the above statements. For an analysis such as this, the optimum angle of attack is roughly $8^{\circ}$.

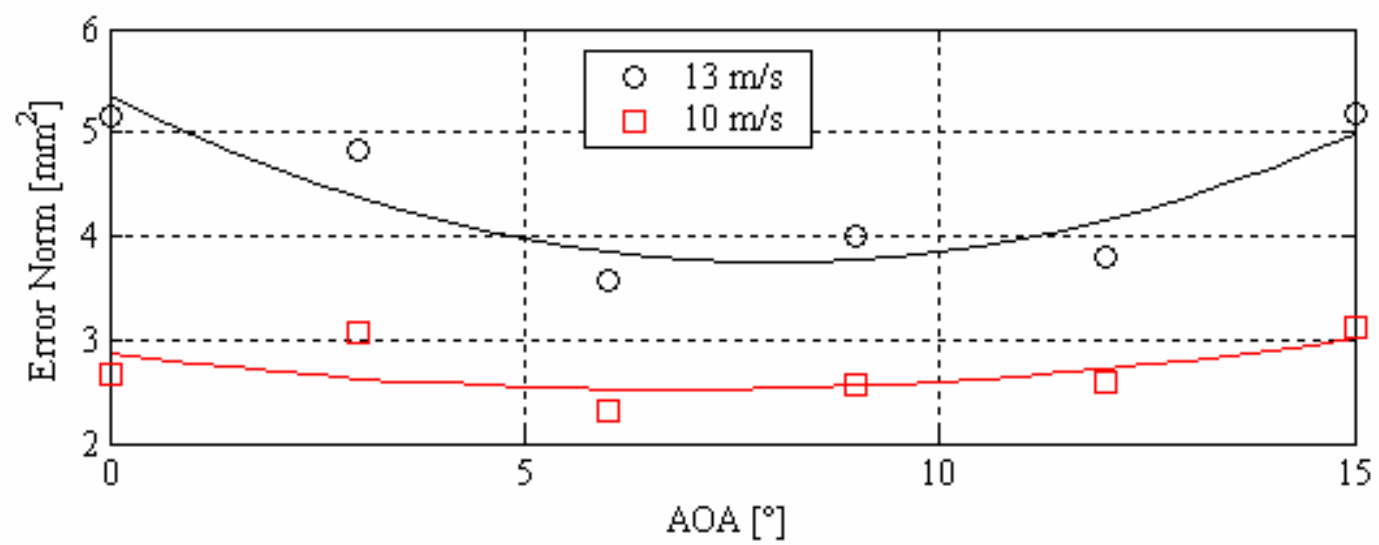

Figure 23. Error norms between experimental and numerical data, for $13 \mathrm{~m} / \mathrm{s}$ and $10 \mathrm{~m} / \mathrm{s}$. Quadratic regressions have been fitted to the data.

\section{Conclusions}

A matrix of wind tunnel tests was performed in order to document the structural deformations of a flexible micro air vehicle. Visual image correlation (VIC) was used to quantify the displacement field over the wing. These experiments were replicated in a numerical sense. The flow and pressures fields were calculated from steady, laminar CFD simulations of a completely rigid wing. Assuming that the change in shape of the membrane wing does not overtly re-distribute the pressure field, the remaining iterations of the fluid-structure interaction were neglected. These pressures are then fed into a structural model, and the computed wing displacements are compared with experimental values. The correspondence between the two sets of data was, in general, quite close. Slight error build-ups were seen at very low AOA (due to experimental noise), and very high AOA (due to model invalidation).

Future work will include deducing the exact effect of pressure re-distribution as a function of membrane billowing. This can be done by carrying out the remaining iterations of the fluid-structure interaction problem: recompute the pressure distribution over the deformed wing, etc. Additionally, work will be done to improve on the aforementioned noise issues pertaining to the VIC system at low angles of attack.

\section{Acknowledgments}

The authors would like to acknowledge the technical contributions of Martin Waszak at the NASA Langley Research Center as well as funding. Furthermore, we would like to thank AFOSR and AFRL for their sponsorship.

\section{References}

${ }^{1}$ Albertani, R. et al, "University of Florida Biologically Inspired MAV," University of Florida, MAE Dept., 8th International MAV Competition, University of Arizona, 2004.

${ }^{2}$ Ifju, P. G., Ettinger, S., Jenkins, D. A., \& Martinez, L., "Composite Materials for Micro Air Vehicles," Proceeding for the SAMPE Annual Conference, Long Beach CA, May 6-10, 2001.

${ }^{3}$ Albertani, R., Stanford, B., Hubner, J. P., Ifju, P., "Aerodynamic Characterization and Deformation Measurements of a Flexible Wing Micro Air Vehicle," 2005 SEM Annual Conference, Paper 302, 10 pages, 2005

${ }^{4}$ Lian, Y., Shyy, W., Ifju, P. G., "Membrane Wing Model for Micro Air Vehicles," AIAA Journal, Vol. 41, No. 12, pp.24922494, Dec. 2003.

${ }^{5}$ Fleming, G. A., Burner, A. W., "Deformation Measurements of Smart Aerodynamic Surfaces," SPIE Paper No. 3783-25, $44^{\text {th }}$ Annual SPIE International Symposium on Optical Science, Engineering, and Instrumentation, Denver, CO, July 18-23, 1999 
${ }^{6}$ Sutton, M. A., Cheng, M., Peters, W. H., Chao, Y. J. and McNeill, S. R., ”Application of an optimized digital correlation method to planar deformation analysis," Image and Vision Computing, 4(3), pp. 143-151, 1986.

${ }^{7}$ Sutton, M. A., Turner, J. L., Bruck, H. A., Chae, T. A., "Full field representation of the discretely sampled surface deformations for displacement and strain analysis,“"Exp. Mech.,:31(2): 168-77, 1991

${ }^{8}$ Albertani, R., Stanford, B., Hubner, P., Lind, R., Ifju, P., "Experimental Analysis of Deformation for Flexible-Wing Micro Air Vehicles," 2005 AIAA SDM Conference, Austin, TX, May, 2005

${ }^{9}$ Albertani, R., Hubner, J.P., Ifju, P.G., Lind, R., Jackowski, J., "Experimental Aerodynamics of Micro Air Vehicles," SAE World Aviation Congress and Exhibition, Paper 04AER-8, 7 pages, Nov 2004.

${ }^{10}$ Sutton, M. A., McFadden, C., "Development of a methodology for non-contacting strain measurements in fluid environments using computer vision," Optics and Lasers in Engineering, 32, 367-377, 2000

${ }^{11}$ Thakur, S., Wright, J., and Shyy, W. "STREAM: A Computational Fluid Dynamics and Heat Transfer Code for Complex Geometries. Part1: Theory. Part 2: User's Guide" University of Florida Gainesville, FL.

${ }^{12}$ Shyy, W., "Computational Modeling for Fluid Flow and Interfacial Transport", Elsevier, Amsterdam, 1994

${ }^{13}$ Viieru, D., Albertani, R., Shyy, W., Ifju, P., "Effect of Tip Vortex on Wing Aerodynamics of Micro Air Vehicles," $22^{\text {nd }}$ AIAA Applied Aerodynamics Conference and Exhibit, Providence, RI, 2004

${ }^{14}$ Jenkins, C.H., editor, "Gossamer Spacecraft: Membrane/Inflatable Structure Technology for Space Applications," AIAA Progress in Astronautics and Aeronautics Series, Vol. 191, 2001

${ }^{15}$ Cook, R.D., Malkus, D.S., Plesha, M.E., Witt, R.J., "Concepts and Applications of Finite Element Analysis," John Wiley \& Sons, New York, New York, 2002 